\title{
Análises de tipos de relevo e solos propícios à ocorrência de Rhinodrilus Motucu Righi em municípios goianos segundo relatos populares
}

\author{
Relief types and favorable soils analysis for occurrence of Rhinodrilus Motucu Righi \\ in goianos municipalities stated by popular narrations
}

\author{
Thiago Augusto Mendes ${ }^{1}$, Renata Kerllen Neves de Souza Faria ${ }^{2}$ e Roberto Malheiros ${ }^{2}$
}

${ }^{1}$ Instituto Federal de Educação, Ciência e Tecnologia de Goiás (IFG) - Campus Aparecida de Goiânia e Pontifícia Universidade Católica de Goiás (PUC Goiás) engenhoaugusto@gmail.com

${ }^{2}$ Pontifícia Universidade Católica de Goiás (PUC Goiás) renata.faria9@gmail.com; roberto@pucgoias.edu.br

\section{Resumo}

O Rhinodrilus motucu Righi, é uma espécie de minhocuçu endêmica dos Estados de Goiás, Mato Grosso, Minas Gerais e Tocantins. Atualmente há poucas pesquisas sobre este animal e os locais de ocorrência, até então eram desconhecidos. Com o desenvolvimento da metodologia, obteve-se relatos quanto a ocorrência natural do Rhinodrilus motucu Righi nos municípios do Estado de Goiás. Os relatos são indícios da ocorrência do animal no município e também serviu para avaliar de forma geral a gestão ambiental municipal. Desta forma, foi possível elaborar o mapa de distribuição geográfica do Rhinodrilus motucu Righi, em Goiás. Consoante a isto, os estudos dos fatores ambientais: solo; geomorfologia/relevo; vegetação; precipitação; e clima comprovaram as informações contidas nos mapas geográficos desenvolvidos. A análise destes demonstrou que o solo, do tipo Gleissolos e Plintossolo e Neossolo, em conjunto aos componentes climáticos essenciais para sua formação, são fatores limitantes a essa espécie. Enfim, uma proposta a problemática desta pesquisa é investir em estudos de reprodução em cativeiro do minhocuçu, no manejo adequado e na preservação de várzeas e veredas.

Palavras-chave: Minhocuçu; Fatores Ambientais; Distribuição Geográfica

\section{Abstract}

The Rhinodrilus motucu Righi, is a species of endemic minhocuçu present on the states of Goiás, Mato Grosso, Minas Gerais and Tocantins. Currently there is little research about this specie and the places of occurrence even were unknown. With the development of the methodology, we obtained reports regarding the natural occurrence of Rhinodrilus motucu Righi on cities of the state of Goias. The reports are indications of the occurrence of the animal in the county and served for a general evaluation of the municipal environmental management. Thus, it was possible to produce a map of the geographical distribution Rhinodrilus motucu Righi, in Goiás Depending on this, the studies of environmental factors: soil; geomorphology/relief; vegetation; precipitation and climate proved developed the information contained in geographic maps. The analysis of these showed that the soil type and the Gleisoil Plinthosoil and Neosoil together with the climatic components essential for their formation, are limiting factors to such species. Finally, a proposal for the issue of this research is to invest in studies of captive breeding of minhocuçu, the proper management and conservation of trails and floodplains.

Keywords: Minhocuçu; Environmental Factors; Geographic Distribution 


\section{Introdução}

Atualmente existem 52 espécies de minhocuçus no Brasil, desse total apenas duas são da família Ocnerodrilidae, as demais pertencem à família Glossoscolecidae, principalmente aos gêneros Glossoscolex e Rhinodrilus (BROWN e JAMES, 2007). Destas, apenas 5 espécies possuem comprimento maior do que um metro, enquanto espécies com 30 a 50 centímetros são relativamente comuns. Embora minhocas com grandes dimensões sejam encontradas em todos os continentes, estas são, aparentemente, mais numerosas no Brasil (BROWN et al., 2006).

Schiedeck et al. (2010) constataram que o nome popular do animal em estudo é derivado da língua tupi-guarani, onde açu significa grande. Minhocaçu ou minhocuçu é uma determinada espécie de minhoca maior em tamanho e diâmetro, ou seja, um animal com os mesmos hábitos.

A espécie Rhinodrilus motucu Righi pertence ao grupo das Oligochaetas (minhocas) com registros da sua distribuição nos Estados de Goiás, Mato Grosso, Minas Gerais e Tocantins. Este animal apresenta uma estrutura corporal de aproximadamente $25,7 \mathrm{~cm}$ de comprimento por 9,5 mm de diâmetro, apresenta coloração no dorso de violeta escura, quase negra e o ventre é de tonalidade parda clara (RIGHI, 1971). A sua reprodução inicia-se juntamente com o período chuvoso. O gênero Rhinodrilus mantém uma relação muito complexa com o ambiente onde vive, esta relação tem dificultado o manejo da espécie em cativeiro (DRUMOND, 2008).

O minhocuçu Rhinodrilus motucu Righi é uma espécie que até o momento tem sido explorada de forma clandestina e desordenada, colocando em risco o extermínio da espécie, antes mesmo de realizar estudos mais detalhados sobre o seu manejo em áreas preservadas. Este animal é utilizado principalmente para prática da pesca.

A Lei Federal de Proteção à Fauna 5.197/1967 proíbe a extração de espécies protegidas por Lei em ambiente natural e a Lei Federal de Crimes Ambientais 9.605/1998 dispõe sobre espécies ameaçadas de extinção, caracterizando sua extração e comercialização como tráfico de animais silvestres, sujeito a pena que vai de multa a detenção de 6 meses a um ano. O minhocuçu, Rhinodrilus motucu Righi se enquadra nas respectivas legislações.

Drumond (2008) realizou o mapeamento, em Minas Gerais, da Rhinodrilus alatus Righi que atualmente consta na lista de animais ameaçados de extinção. Bronw et al. (2012) encontraram um exemplar, em Minas Gerais, da Rhinodrilus fafner Michaelseni, animal considerado extinto segundo o Livro Vermelho da Fauna Brasileira Ameaçada de Extinção - Invertebrados Terrestres (MMA, 2008).

Com a mesma perspectiva, o mapeamento das áreas de ocorrência da espécie Rhinodrilus motucu Righi, no Estado de Goiás servirá de subsídios ao trabalho dos órgãos fiscalizadores, apontando os locais de ocorrência da espécie. Com os dados geográficos pode-se elaborar soluções para a criação de áreas para exploração e manejo sustentável da espécie, comprovado o potencial econômico que o minhocuçu oferece, recomendando-se uma nova fase para a preservação e a diminuição dos riscos de extinção da espécie que é explorada de forma intensiva e desordenada.

O objetivo principal deste artigo foi estabelecer a distribuição geográfica do Rhinodrilus motucu Righi no Estado de Goiás e demonstrar os resultados por meio de mapas, elaborados com ferramentas georreferenciadas. Secundariamente, objetiva-se identificar o habitat da espécie, através da análise de fatores ambientais. A presente pesquisa também teve a intenção de auxiliar no estudo de criação do minhocuçu em cativeiro, projetos de criação de unidades de manejo, exploração sustentável da espécie, bem como contribuir para a fiscalização dos órgãos ambientais.

\section{Fundamentação Teórica}

No Brasil existem minhocuçus de duas famílias distintas, estas são Ocnerodrilidae e Glossoscolecidae, dentro desta última encontram-se os gêneros Glossoscolex e Rhinodrilus (SCHIEDECK et al., 2010). A espécie Rhinodrilus motucu Righi ocorre no Estado de Goiás, mas não existem dados concretos sobre a distribuição geográfica da espécie (DRUMOND, 2008).

Os minhocuçus chamam atenção tanto por suas peculiaridades morfológicas e anatômicas quanto pelo papel que desempenham na natureza. Desde a antiguidade, a importância das minhocas já era reconhecida por gregos e egípcios (MINNICH, 1977; RIGHI, 1971). Porém, coube a Charles Darwin, em seu trabalho "The formation of vegetable mould through the action of worms with observations on their habits" de 1881, dar às minhocas um lugar de destaque no processo de pedoturbação e ciclagem da matéria orgânica do solo (FELLER et al., 2003 apud SCHIEDECK et al., 2010).

A primeira minhoca a ser descrita no Brasil foi um exemplar com mais de um metro de comprimento, da espécie Glossoscolex giganteus, no Rio de Janeiro (JAMES e BROWN, 2006). Já a maior minhoca coletada no país foi um exemplar da espécie Rhinodrilus fafner Righi, com 2,1 metros de comprimento, capturada próxima à cidade de Belo Horizonte, Minas Gerais (MICHAELSEN, 1918).

A abrangência de metodologias para o estudo e a conservação da diversidade biológica está intimamente ligada aos estudos biogeográficos (PRANCE, 2000). A biogeografia, quando analisada no contexto de conservação, descreve padrões de distribuição de espécies, identificando áreas com riqueza e endemismos, comparando a composição biológica nas diferentes áreas, e identificando bases genéticas e evolutivas para a manutenção da diversidade (CRISCI et al., 2003). 
Segundo a Lei Federal de Crimes Ambientais 9.605/1998, comercializar ou transportar espécimes da fauna silvestre, sem a devida permissão, licença ou autorização da autoridade competente constitui crime ambiental. O tráfico ilegal de vida silvestre representa o terceiro maior negócio ilícito do mundo, perdendo apenas para o tráfico de drogas e armas (ReNCTAS, 2001).

Alguns pesquisadores do Instituto Brasileiro do Meio Ambiente e dos Recursos Naturais Renováveis (IBAMA) defendem que a inclusão do minhocuçu na lista foi feita de maneira equivocada, pois algumas espécies, como a Rhinodrilus alatus Righi, são encontradas em diversos municípios de Minas Gerais e a ocorrência de exploração comercial a mais de 70 anos por muitas populações tradicionais, que dependem da atividade para sustentar suas famílias. Porém, enquanto a medida não for revista, seu uso permanece proibido, embora a exploração e comercialização continuem em muitos municípios (DRUMOND, 2008).

As minhocas podem representar de 40 a $90 \%$ da macrofauna invertebrada em ecossistemas naturais (LAVELLE et al., 1994). Esses animais estão entre os organismos do solo mais diretamente relacionados à nutrição mineral, crescimento e produção das plantas (LEE, 1985).

Os invertebrados são mediadores de diversos processos biológicos que resultam em melhor ambiente para o crescimento das plantas (LAVELLE et al., 2006). As minhocas (classe Oligochaeta, filo Annelida), junto a formigas e cupins, são reconhecidas como "engenheiras do ecossistema" (JONES et al., 1994; LAVELLE et al., 1994), pois suas atividades resultam na criação de estruturas biogênicas (galerias, ninhos, câmaras e coprólitos) que modificam as propriedades físicas do solo onde vivem, bem como exercem influência na disponibilidade de recursos para outros organismos, incluindo microrganismos e plantas.

Drumond (2008) em parceria com Ministério Público de Minas Gerais, Instituto Brasileiro de Meio Ambiente e Recursos Naturais Renováveis (IBAMA), Instituto Estadual de Florestas de Minas Gerais (IEFMG), Secretaria de Estado do Meio Ambiente e Desenvolvimento Sustentável (SEMAD) e prefeituras de Paraopeba - MG e Caetanópolis - MG realizaram estudo da distribuição geográfica da Rhinodrilus alatus Righi, concluindo que esta espécie habita somente a região central de Minas Gerais, conforme Figura 1.

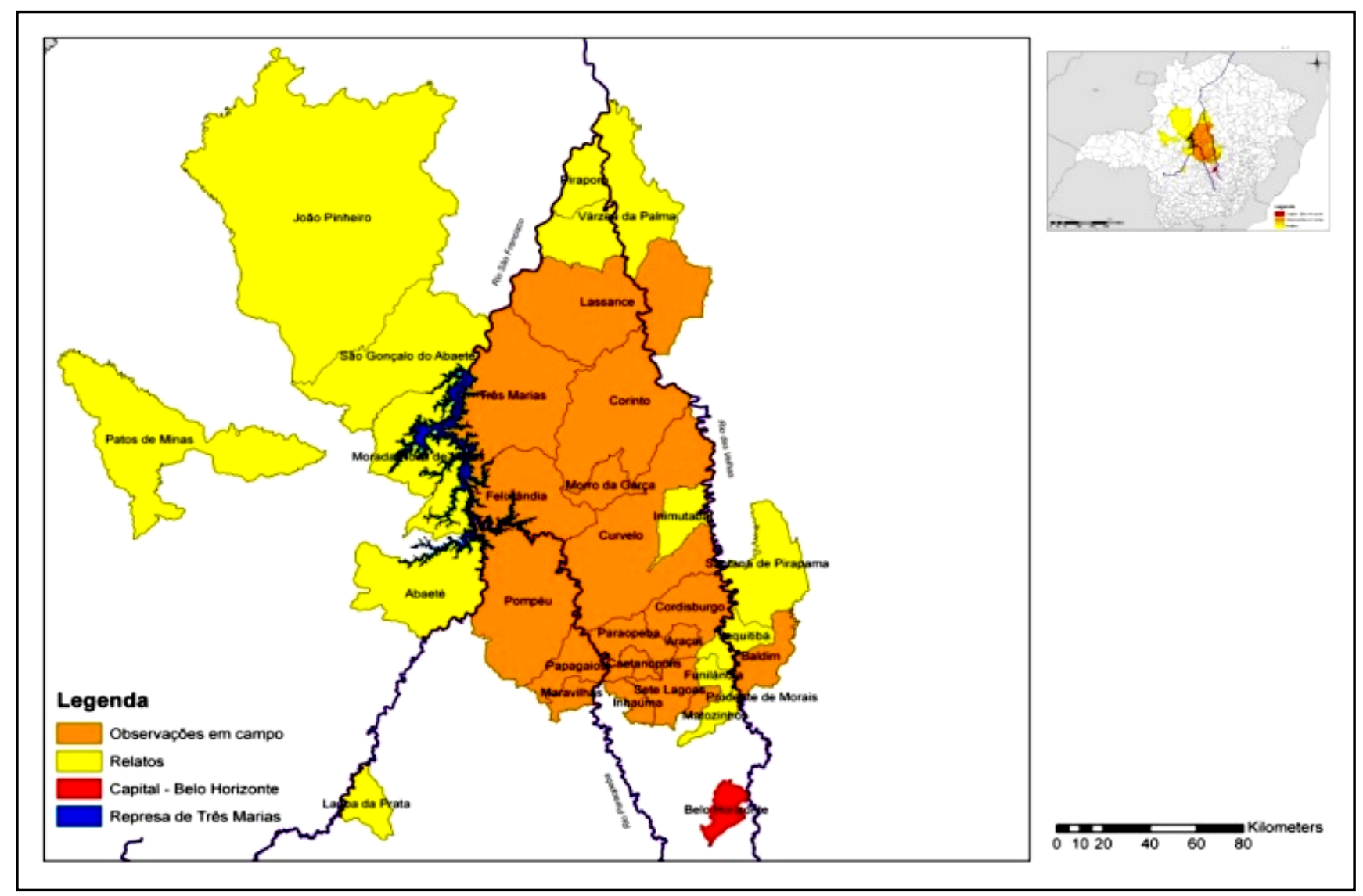

Figura 1 - Municípios do Estado de Minas Gerais com ocorrência comprovada (DRUMOND, 2008.)

Brown et al. (2012) constataram que o minhocuçu Rhinodrilus fafner Michaelsen, é uma espécie de minhoca endêmica do Estado de Minas Gerais e após ser inscrita no Livro Vermelho como animal extinto foi encontrado um exemplar, em Sabará - MG, no Bairro Gorduras, nos arredores de Belo Horizonte - MG. 


\section{Metodologia}

O estudo da distribuição geográfica do minhocuçu (Rhinodrilus motucu Righi), no Estado de Goiás, foi desenvolvido com base na coleta e tabulação dos dados provenientes de quatro etapas. A primeira etapa foi composta por pesquisas bibliográficas em livros, revistas e artigos publicados, relacionados à Oligochaeta; visita e consulta aos relatórios internos dos órgãos ambientais: Instituto Brasileiro do Meio Ambiente e dos Recursos Naturais Renováveis (IBAMA); Secretaria do Meio Ambiente e dos Recursos Hídricos (SEMARH) e Delegacia Estadual de Repressão a Crimes Contra o Meio Ambiente (DEMA). Além disso, foram realizados levantamentos e relatórios informais com pescadores profissionais e amadores; questionamentos verbais (entrevistas) junto a extratores e comerciantes de iscas vivas a respeito do local de extração, da morfologia e do habitat do animal.

Na segunda etapa, foram aplicados questionários verbais e online (via telefone e e-mail) nas Agências/Secretarias Municipais do Meio Ambiente (AMMA) e na Empresa de Assistência Técnica e Extensão Rural de Goiás (EMATERGO) dos municípios do Estado de Goiás. A terceira etapa envolveu análises dos dados coletados na primeira e na segunda etapa para elaboração do mapa de distribuição geográfica do Rhinodrilus motucu Righi no Estado de Goiás, desenvolvido no software ArcGIS, versão 10.2.

Para o estudo dos elementos da natureza utilizou-se cartas e shapes topográficos de temperatura e solo do Sistema Estadual de Geoinformação de Goiás (SIEG), de relevo e precipitação do Serviço Geológico do Brasil (CPRM) e da vegetação do Ministério do Meio Ambiente (MMA). Os resultados em forma de mapas (shapes) também foram elaborados na plataforma GIS. E por último (quarta etapa), os dados apresentados na terceira etapa, foram comparados com os componentes naturais encontrados nos shapes para análise dos componentes da natureza e identificação do habitat da espécie motucu.

\section{Resultado e Discussões}

A primeira etapa da metodologia resultou em informações sobre distribuição geográfica da espécie Rhinodrilus motucu Righi no estado de Goiás. Através de visitas realizadas em Casas de Iscas Vivas na capital goiana com intuito de saber o local de onde é extraído o animal, assim como as caraterísticas de seu habitat e os aspectos morfológicos da espécie. Foram visitados e entrevistados 5 estabelecimentos que comercializavam minhocuçus na capital goiana.

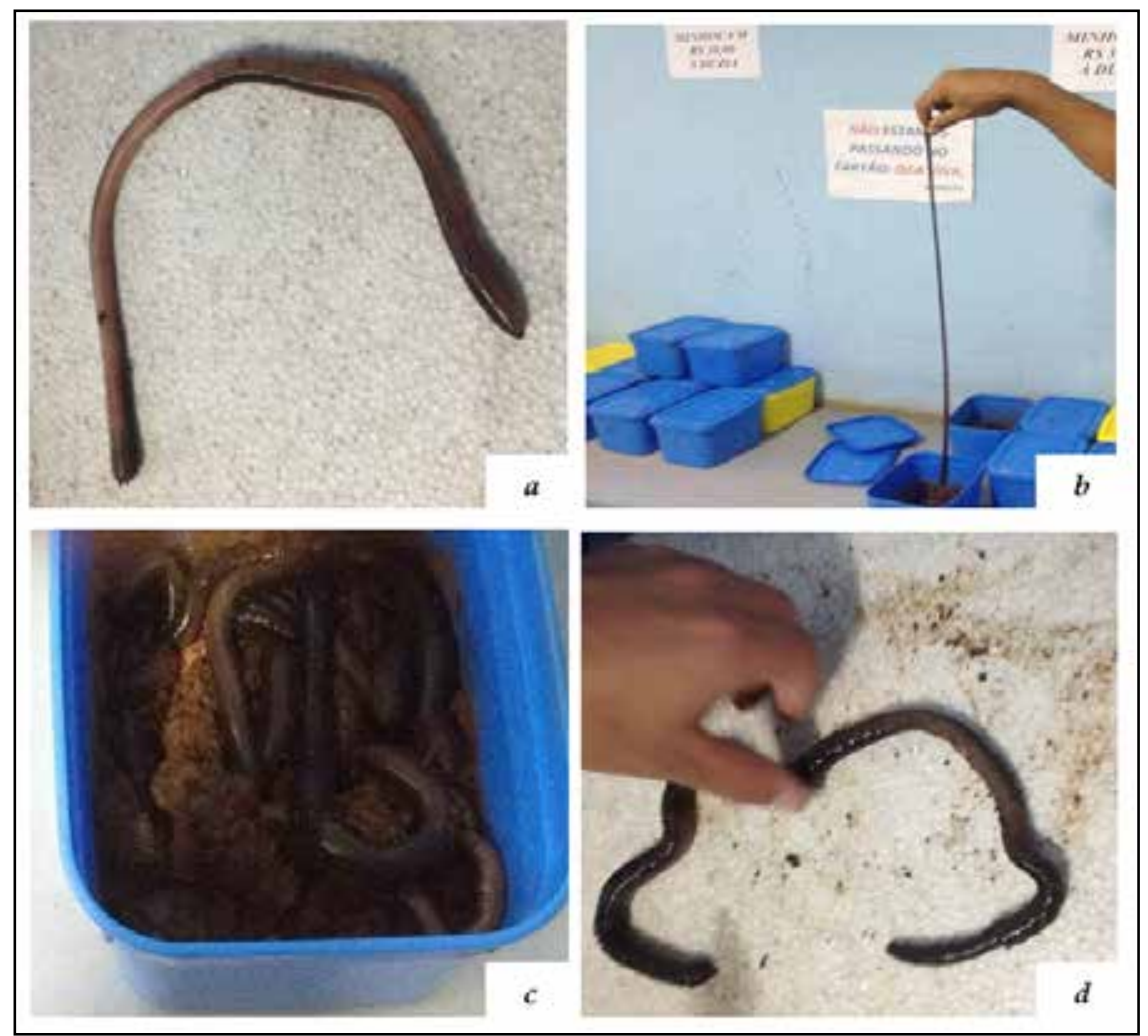

Figura 2 - Minhocuçus comercializadas na capital goiana (a) Minhocuçu tamanho "P"; (b) Minhocuçu tamanho "G"; (c) Embalagem para venda dos minhocuçus; (d) Minhocuçu morto no armazenamento 
Como exemplo das conversas informais, ao entrevistar o comerciante de uma determinada Casa de Iscas, o mesmo foi informado que a finalidade da conversa seria para acrescentar informações a presente pesquisa. O comerciante relatou que não utiliza o nome minhocuçu no estabelecimento, pois conhecia a legislação que proíbe a venda do animal, deste modo, nesta casa de iscas distinguem-se as minhocas por tamanho P (pequeno), M (médio) e G (grande), conforme mostra a Figura 2a a 2d, registrada durante a visita in loco.

O comerciante relatou que a minhoca do tamanho G, pode chegar até $1,5 \mathrm{~m}$ e é coletada na região de Porangatu - GO. Segundo ele, as minhocas G, são retiradas de solos secos do cerrado, diferentemente das minhocas P e M que são encontradas em solos úmidos.

Na Secretaria de Meio Ambiente de Recursos Hídricos do Estado de Goiás (SEMARH), na Delegacia Estadual de Repressão a Crimes Contra o Meio Ambiente (DEMA) e na Agência Municipal de Meio Ambiente de Goiânia (AMMA) não foi obtida nenhuma informação sobre a espécie do minhocuçu que habita os solos goianos, o local de ocorrência e se há criadores registrados. Somente o Instituto Brasileiro do Meio Ambiente e Recursos Naturais Renováveis (IBAMA) tinha relatos sobre à espécie, porém, na forma de duas autuações em lojas especializadas em iscas no município de Porangatu-GO.

Com a segunda etapa da metodologia, foi possível verificar que dos 246 municípios goianos, 146 municípios goianos informaram através de seus órgãos ambientais sobre a existência ou não da espécie (minhocuçu), dos quais 107 municípios informaram que não há relatos da presença do minhocuçu e 39 municípios relataram a ocorrência do animal não sabendo a qual espécie se enquadrava. O Quadro 1 mostra as informações que foram repassadas pelos Responsáveis de Órgãos Ambientais e Agropecuários Municipais ou profissionais responsáveis pela gestão ambiental dos municípios pesquisados.

Quadro 1 - Ocorrência* de minhocuçu no estado de Goiás

\begin{tabular}{|c|c|c|c|}
\hline Município & Representante & $\begin{array}{c}\text { Órgão } \\
\text { Ambiental }\end{array}$ & Características \\
\hline Alto Horizonte & Jocemar Mota & SEMMA & $\begin{array}{c}\text { Áreas úmidas. Existem duas qualidades de minhocuçu no } \\
\text { município. }\end{array}$ \\
\hline Amorinópolis & $\begin{array}{l}\text { João Machado } \\
\text { de Rezende }\end{array}$ & SEMMA & $\begin{array}{l}\text { Tem aproximadamente } 20 \mathrm{~cm} \text { tamanho e } 8 \mathrm{~mm} \text { diâmetro. } \\
\text { Cor preta e bastante agitada. Geralmente encontrada em } \\
\text { veredas onde a terra é preta e fofa. }\end{array}$ \\
\hline Anhanguera & Lucas & SEMMA & Escura. Em brejos \\
\hline Aragarças & Gilnei & SEMMA & $\begin{array}{l}\text { Escura. Média } 30 \mathrm{~cm} \text { de tamanho e } 1 \mathrm{~cm} \text { de diâmetro. Brejo. } \\
\text { Está desaparecendo com o tempo. }\end{array}$ \\
\hline Aragoiânia & João & $\begin{array}{l}\text { Corretória } \\
\text { Municipal }\end{array}$ & $\begin{array}{l}\text { Muito raro encontrar. Cor escura. Média tamanho } 25 \mathrm{~cm} \text { e } \\
\text { diâmetro de } 9 \mathrm{~mm} \text {. }\end{array}$ \\
\hline Araguapaz & $\begin{array}{l}\text { Fernando Eric } \\
\text { Barbosa }\end{array}$ & SEMMA & Em abundância. O minhocuçu prefere solo vermelho e roxo. \\
\hline Arenópolis & Devailton & SEMMA & Encontrado em Brejo \\
\hline Baliza & Rondon & SEMMA & Próximo a curso d'água. \\
\hline Buriti de Goiás & Jhonata & SEMMA & Área úmida, perto de vazantes e terrenos arenosos. \\
\hline Campos Verdes & Antônio & SEMMA & $\begin{array}{l}\text { Partes baixas. Solo de cultura. Preta de aproximadamente } \\
\qquad 20 \mathrm{~cm} \text { de tamanho e } 9 \mathrm{~mm} \text { de diâmetro. }\end{array}$ \\
\hline $\begin{array}{l}\text { Carmo do Rio } \\
\text { Verde }\end{array}$ & José Wilson & EMATER & $\begin{array}{l}\text { Muito raro. Cor vermelho claro, aprox. } 30 \mathrm{~cm} \text { de tamanho e } \\
\text { 9mm de diâmetro; perto de curso d'água. }\end{array}$ \\
\hline $\begin{array}{l}\text { Cidade } \\
\text { Ocidental }\end{array}$ & Humberto Jorge & SEMMA & $\begin{array}{l}\text { Áreas mais úmidas, com bastante matéria orgânica. Animal } \\
\text { escuro; comprimento } 20 \mathrm{~cm} \text { e diâmetro } 7 \mathrm{~mm} \text {. }\end{array}$ \\
\hline Colinas do Sul & Luiz Carlos & EMATER & Já ouviu falar, mas não se encontra mais. \\
\hline
\end{tabular}


Continuação Quadro 1 - Ocorrência* de minhocuçu no estado de Goiás

\begin{tabular}{|c|c|c|c|}
\hline Município & Representante & $\begin{array}{c}\text { Órgão } \\
\text { Ambiental }\end{array}$ & Características \\
\hline $\begin{array}{c}\text { Divinópolis de } \\
\text { Goiás }\end{array}$ & Tales & SEMMA & Muito raro. Em brejos. \\
\hline Estrela do Norte & Uanderson Vieira & SEMMA & $\begin{array}{c}\text { Cor vermelha. Próximo a curso d'água, } \\
\text { de aproximadamente } 20 \mathrm{~cm} \text { e } 8 \mathrm{~mm} \text { de } \\
\text { diâmetro. }\end{array}$ \\
\hline Flores de Goiás & Lucydário & EMATER & Em abundância. \\
\hline Formosa & Raimundo & SEMMA & $\begin{array}{l}\text { Já ouviu falar a muito tempo atrás, em } \\
\text { áreas de lavouras. }\end{array}$ \\
\hline Goianápolis & José Divino & SEMMA & Escassa. \\
\hline Goianésia & Pedro Inácio & SEMMA & Veredas. \\
\hline Município & Representante & $\begin{array}{c}\text { Órgão } \\
\text { Ambiental }\end{array}$ & Características \\
\hline Goiânia & Vitor & EMATER & $\begin{array}{l}\text { Lago Verde (Região sudoeste da capital } \\
\text { goiana). }\end{array}$ \\
\hline Goianira & José & SEMMA & $\begin{array}{l}\text { Por telefone disse que sim, e solicitou } \\
\text { enviar e-mail que responderia com as } \\
\text { características, mas não respondeu. }\end{array}$ \\
\hline Cidade de Goiás & Colemar & EMATER & $\begin{array}{c}\text { Ele mesmo já encontrou, mas é muito raro; } \\
\text { cor vermelha; encontrado perto d curso } \\
\text { d'água. }\end{array}$ \\
\hline Goiatuba & Lyno & SEMMA & $\begin{array}{l}\text { Ouviu falar, mas não sabe descrever as } \\
\text { características. }\end{array}$ \\
\hline Iaciara & Pedro Teles & EMATER & $\begin{array}{l}\text { Ouviu relatos de produtores rurais terem } \\
\text { encontrado em suas propriedades. }\end{array}$ \\
\hline Itapirapuã & Marcielio & EMATER & $\begin{array}{l}\text { Terra vermelha argilosa e encontra até em } \\
\text { lugares altos de solo seco. Em média de } 15 \\
\text { a } 50 \mathrm{~cm} \text { e diâmetro de } 1 \mathrm{~cm} \text {; marrom escuro. }\end{array}$ \\
\hline Itumbiara & Belchior Gonçalves & EMATER & $\begin{array}{l}\text { Muito raro; cor escura; } 20 \text { a } 30 \mathrm{~cm} \text { e } 9 \mathrm{~mm} \\
\text { de diâmetro. }\end{array}$ \\
\hline Jaupaci & Absalon & EMATER & $\begin{array}{c}\text { Brejo; } 20 \text { a } 25 \mathrm{~cm} \text { e } 9 \mathrm{~mm} \text { de diâmetro; Cor } \\
\text { escura. }\end{array}$ \\
\hline Mara Rosa & Eduardo Cavicchioli & EMATER & $\begin{array}{l}\text { Várzeas e área de cultura; cor escura; } 20 \text { a } \\
\qquad 30 \mathrm{~cm} \text { e } 9 \mathrm{~mm} \text { de diâmetro. }\end{array}$ \\
\hline Mimoso de Goiás & Elandes & EMATER & $\begin{array}{l}\begin{array}{l}\text { É muito raro encontrar, mas vivem em } \\
\text { brejo. }\end{array} \\
\end{array}$ \\
\hline Minaçu & Pedro Mesquita & EMATER & $\begin{array}{l}\text { Várzeas. Cor escura de } 20 \text { a } 30 \mathrm{~cm} \text { e } 8 \mathrm{~mm} \\
\text { de diâmetro. }\end{array}$ \\
\hline $\begin{array}{l}\text { Montes Claros de } \\
\text { Goiás }\end{array}$ & Odair Simões & EMATER & $\begin{array}{l}\text { Conhecido com minhocão; encontrado em } \\
\text { brejo; coloração preta de aproximadamente } \\
30 \mathrm{~cm} \text { de comprimento e } 1 \mathrm{~cm} \text { de diâmetro. }\end{array}$ \\
\hline Nova Crixás & & & $\begin{array}{c}\text { Veredas onde a terra é preta e fofa; aprox. } \\
20 \mathrm{~cm} \text { e } 8 \mathrm{~mm} \text { de diâmetro, cor preta e } \\
\text { bastante agitada. }\end{array}$ \\
\hline
\end{tabular}


Continuação Quadro 1 - Ocorrência* de minhocuçu no estado de Goiás

\begin{tabular}{|c|c|c|c|}
\hline Município & Representante & $\begin{array}{c}\text { Órgão } \\
\text { Ambiental }\end{array}$ & Características \\
\hline Novo Brasil & Selma & SEMMA & $\begin{array}{l}\text { Cor grafite escuro; aprox. } 30 \mathrm{~cm} \text { e } 9 \mathrm{~mm} \text { de } \\
\text { diâmetro; próximo a curso d'água. }\end{array}$ \\
\hline Paranaiguara & Antônio Geraldo & EMATER & $\begin{array}{l}\text { Varjões. Porém os pescadores estão } \\
\text { dizimando. Escuro, aproximadamente } 50 \\
\text { cm e } 12 \mathrm{~mm} \text { diâmetro. }\end{array}$ \\
\hline Piranhas & Juarez Ribeiro & Autônomo & $\begin{array}{l}\text { Áreas de varjões; vermelho escuro; } \\
\text { aproximadamente } 25 \mathrm{~cm} \text { e } 9 \mathrm{~cm} \text { de } \\
\text { diâmetro. }\end{array}$ \\
\hline Porangatu & Maria Jaci & SEMMA & $\begin{array}{l}\text { Várzeas, área de cultura; cor escura; } 20 \text { a } 30 \\
\text { cm e } 8 \text { mm de diâmetro. }\end{array}$ \\
\hline Posse & Damásio Amorim & EMATER & $\begin{array}{l}\text { Ouviu relatos que tem somente em um } \\
\text { local, conhecido como Vão Paranã - } \\
\text { Curruá, área seca mas alaga quando o rio } \\
\text { sobe; } 25 \text { a } 30 \mathrm{~cm} \text {; preta da espessura de um } \\
\text { dedo; eles chamam de minhocão. }\end{array}$ \\
\hline Rio Verde & Marlúcio Oliveira & EMATER & $\begin{array}{c}\text { Brejos; Marrom; } 18 \text { a } 25 \mathrm{~cm} \text { de } \\
\text { comprimento e } 8 \mathrm{~mm} \text { de diâmetro. }\end{array}$ \\
\hline Três Ranchos & João Batista & SEMMA & Cerrado. \\
\hline
\end{tabular}

*A palavra OCORRÊNCIA neste artigo, tem o seguinte significado: existe minhocuçu nativo no Estado de Goiás em determinado Município, segundo relatos do Responsável pelo Órgão Municipal.

Nota-se que 39 municípios (26,7\%) relataram sobre a ocorrência do minhocuçu e em apenas 2 municípios (Araguapaz e Flores de Goiás - GO) informaram que é possível encontrar o animal em abundância, conforme mostra a Figura 3.

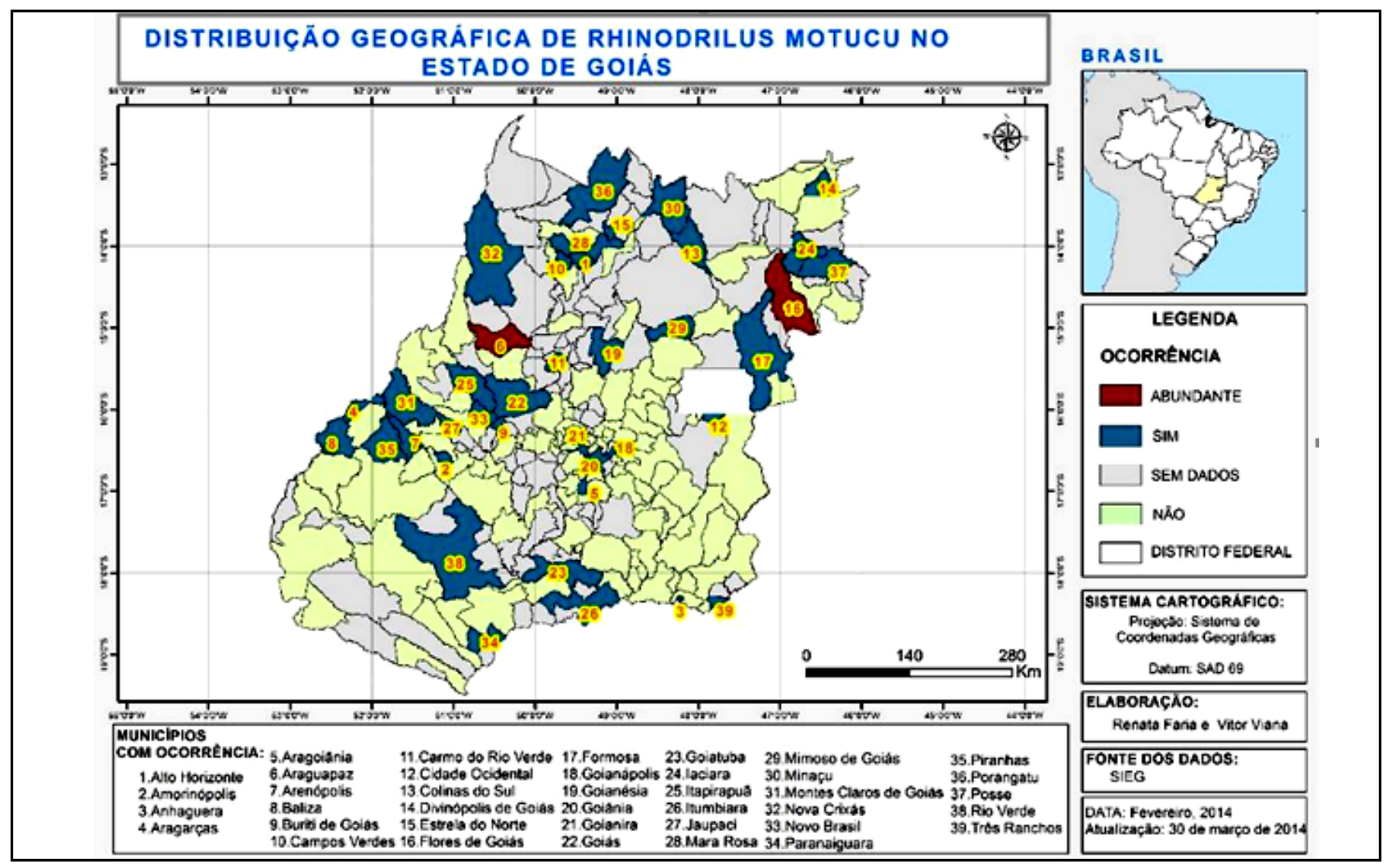

Figura 3 - Distribuição geográfica potencial de Rhinodrilus motucu Righi no estado de Goiás 
O estudo da distribuição geográfica da espécie Rhinodrilus motucu Righi em Goiás, foi realizado através das análises dos mapas de relevo, solo, vegetação, temperatura e precipitação, especificamente nos municípios de Araguapaz, localizado no noroeste do estado de Goiás, e Flores de Goiás, localizada na região do Vão do Paranã, no nordeste goiano, onde é possível encontrar o minhocuçu em abundância. Também foram analisados os fatores ambientais do município de Porangatu , localizado ao norte do estado de Goiás, pois este município é a principal região de extração ilegal do animal, destinando-os a venda para todo o estado de Goiás.

Analisando o mapa de relevo (Figura 4) nota-se que o município de Araguapaz (número 6 no mapa) possui características que vai de plana a ondulada com surgimento de serras e morros.

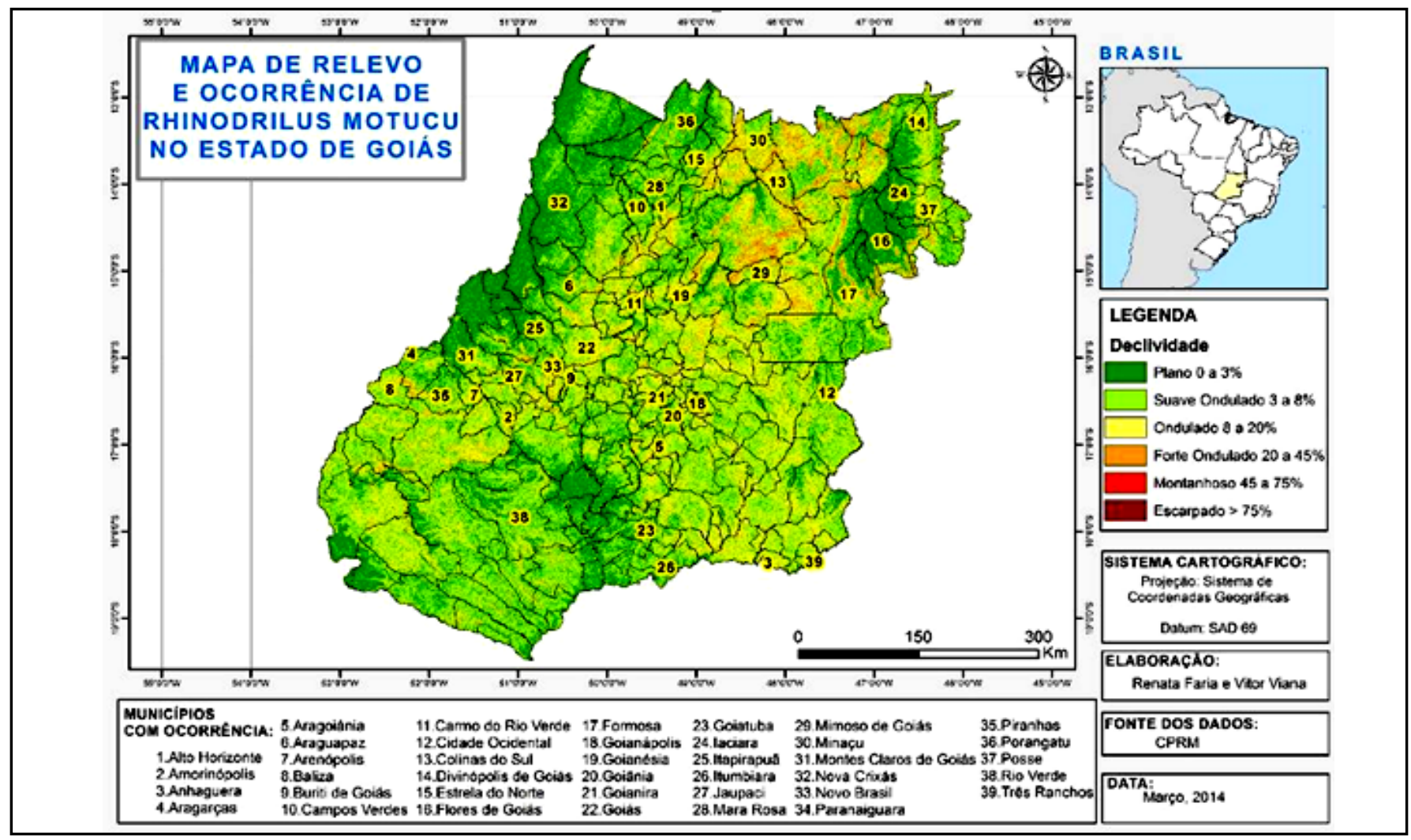

Figura 4 - Mapa de declividades do relevo do estado de Goiás

Em Flores de Goiás - GO (número 16 no mapa) o relevo encontra-se muito aplainado e a leste do município destaca-se uma região acidentada e montanhosa. Porangatu - GO (número 36 do mapa) possui o relevo plano a suavemente ondulado, com poucas áreas com forte ondulação.

A Figura 5 mostra as classes de solos e a Figura 6 mostra a vegetação do estado de Goiás. A Figura 5 mostra que em Araguapaz-GO a categoria de solo predominante é o Cambissolo, com manchas de Latossolo, Neossolo e Plintossolo. Já em Flores de Goiás - GO a classe de solo predominante é Gleissolos, com manchas de Latossolo, Argissolo, Plintossolo e Neossolo. Em Porangatu - GO a categoria predominante de solo é o Latossolo, com manchas de Argissolo, Neossolo e Plintossolo.

Na Figura 6 verifica-se que a vegetação predominante do município de Araguapaz - GO é pastagem, também contendo manchas de cerrado típico e pequena área de cultura. Em Flores de Goiás - GO a vegetação natural predomina, porém há áreas de pastagens. E em Porangatu a vegetação predominante é a pastagem com resquício de vegetação natural.

Observa-se na Figura 7 e Figura 8, a temperatura média e a precipitação média anual dos municípios do Estado de Goiás, respectivamente. Em Araguapaz - GO contatou-se média de temperatura anual de $25,5^{\circ} \mathrm{C}$. Já em Flores de Goiás - GO a temperatura média anual é de aproximadamente $20^{\circ} \mathrm{C}$ e no município de Porangatu - GO a temperatura média anual de $24^{\circ} \mathrm{C}$.

Como mostra a Figura 8, o município de Araguapaz - GO registra uma precipitação média anual de 1300 a 1500 mm. Em Flores de Goiás - GO a precipitação média anual de 1000 a 1300 mm. E em Porangatu - GO a precipitação média anual de 1400 a 1600 mm. 


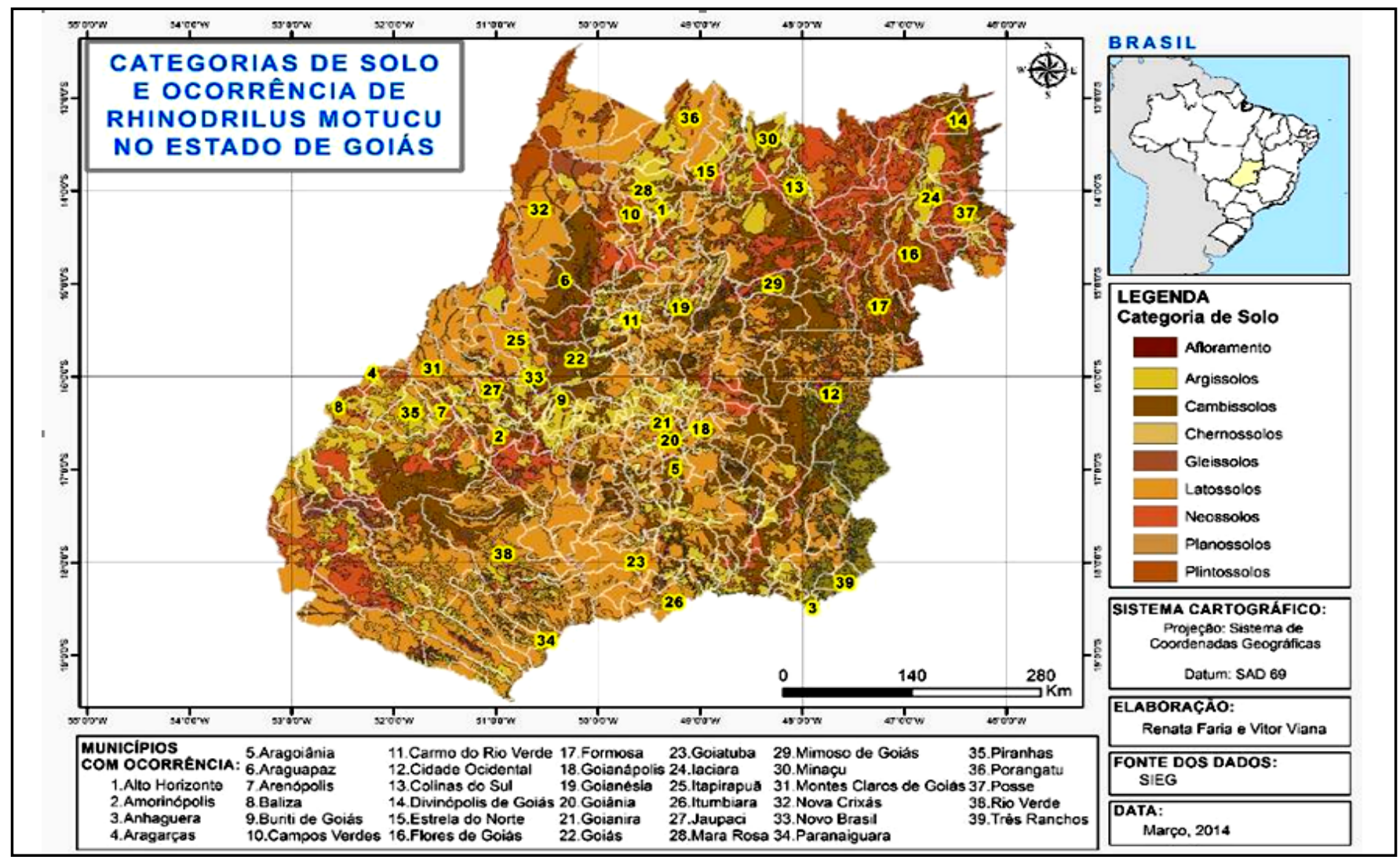

Figura 5 - Mapa de categorias (classes) de solo do estado de Goiás

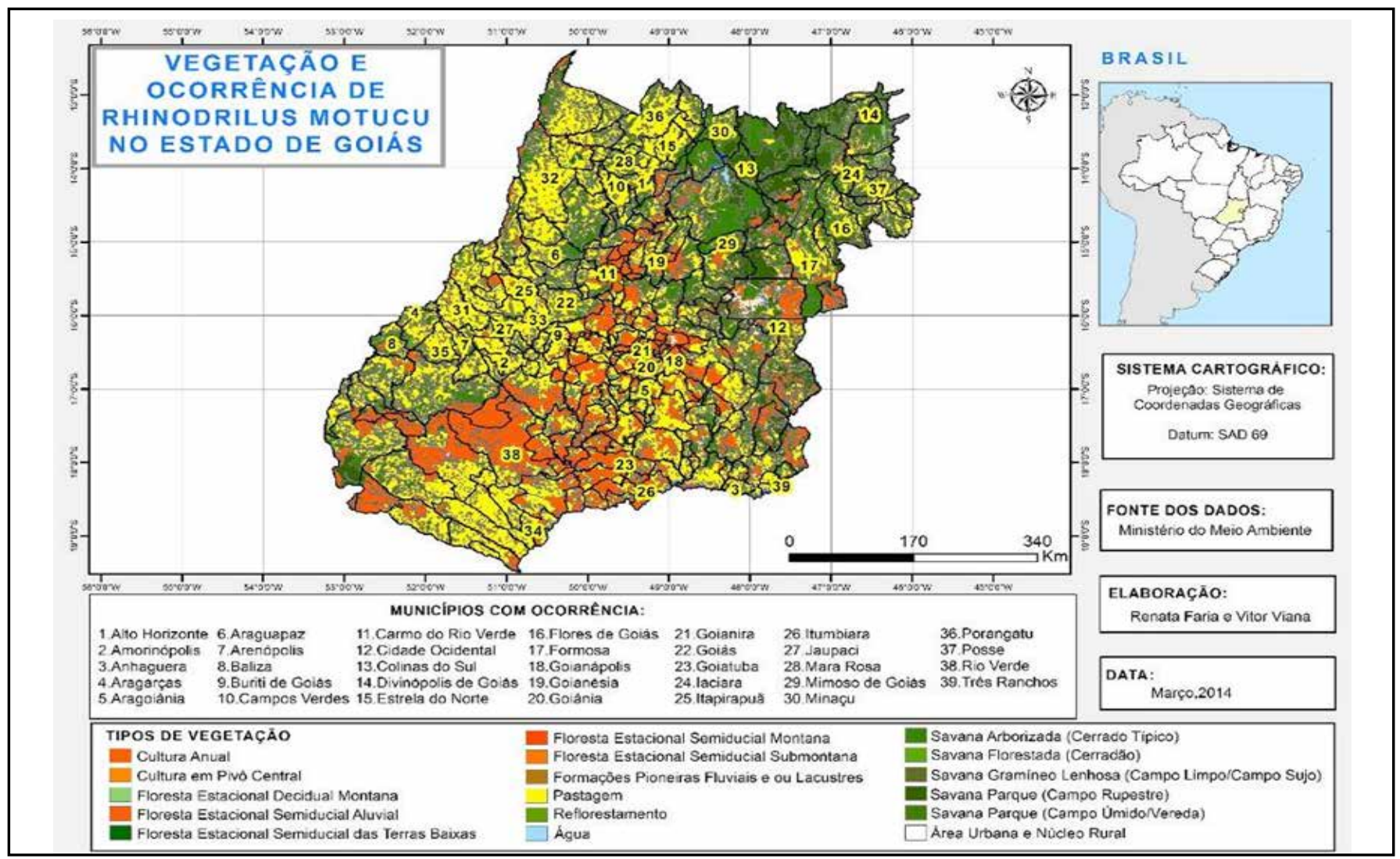

Figura 6 - Mapa de vegetação do estado de Goiás 


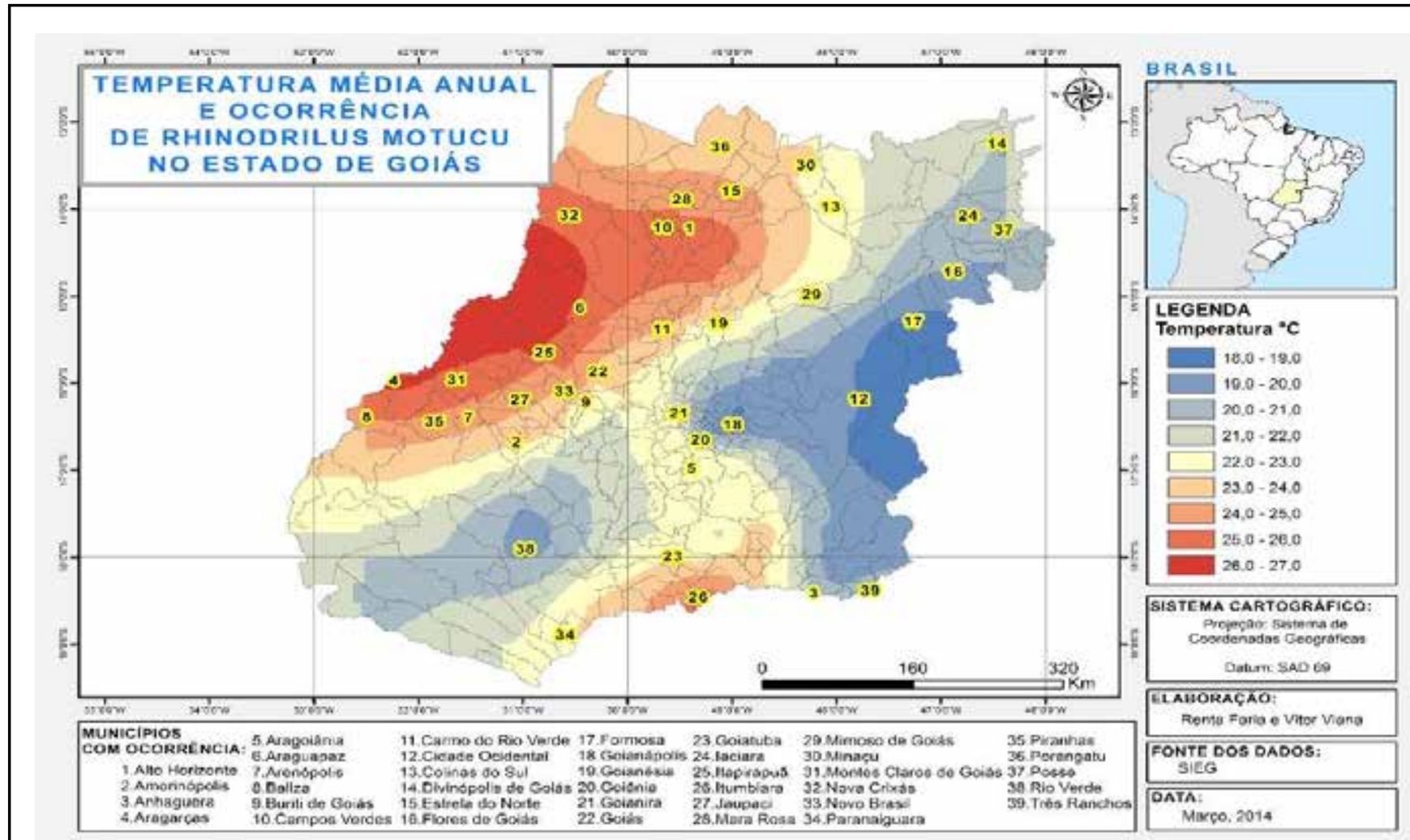

Figura 7 - Mapa de temperatura média anual do estado de Goiás

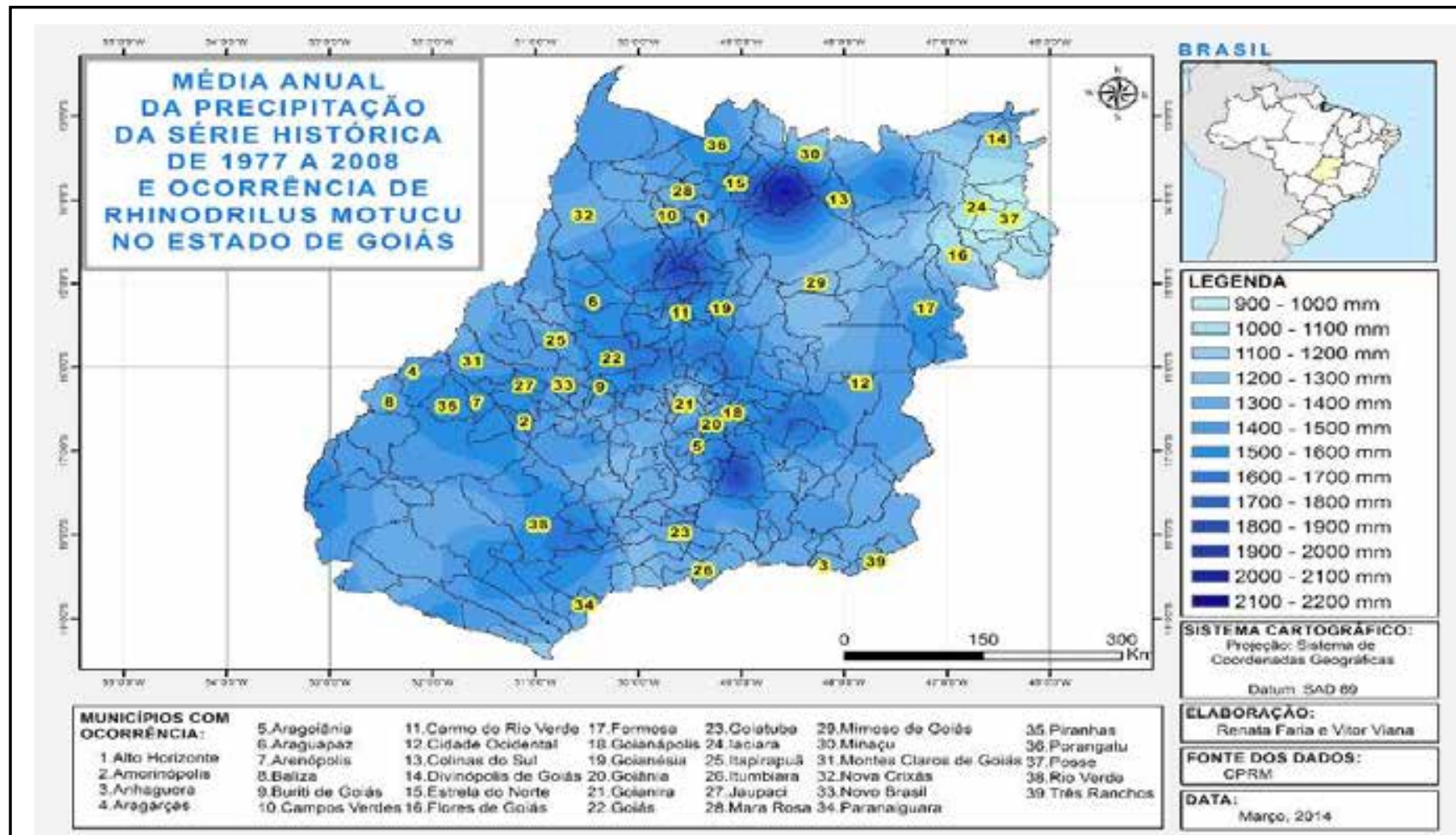

Figura 8 - Mapa de precipitação média anual do estado de Goiás 
Ainda com relação ao estudo do relevo dos locais onde é possível encontrar o minhocuçu em Goiás, também foram analisados os tipos de rochas, consultando o Livro de Geomorfologia do Sistema Estadual de Geoinformação de Goiás - SIEG (LATRUBESSE e CARVALHO, 2006), onde ressalta que a Superfície Regional de Aplainamento - SRA, são as unidades mais representativas da geomorfologia do estado de Goiás. Nesse contexto, foram identificadas quatro superfícies de aplainamento distintas.

A quarta superfície de aplainamento, conforme representa a Figura 9, envolve a maioria dos municípios de onde há relatos da existência do minhocuçu nativo, apresentando as seguintes características: localizam-se principalmente no noroeste, oeste, nordeste e centro sul do estado de Goiás e desenvolve-se sobre rochas pré-cambrianas e grande variedade de rochas do embasamento cristalino, possui geração de relevos muito aplainados e apresentam-se níveis de lateritas desenvolvidas. As unidades associadas às características geomorfológicas são os sistemas lacustres e os cársticos, quando desenvolvidos sobre rochas bambuí e unidades de morros e colinas.

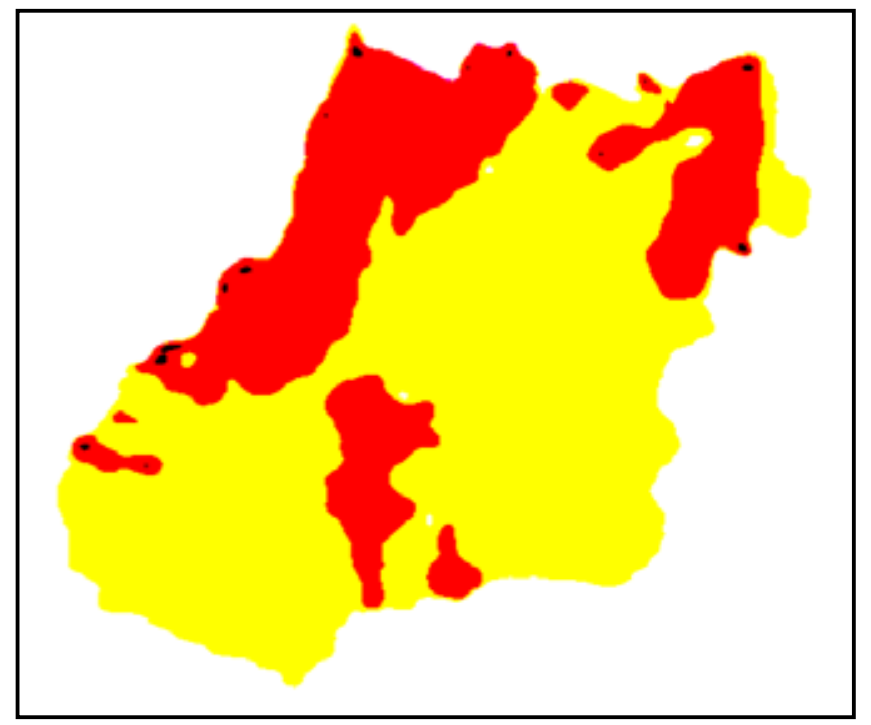

Figura 9 - Superfície Regional de Aplainamento SRAIV (LATRUBESSE e CARVALHO, 2006)

Durante visita técnica em área particular próxima ao setores Jardins Madri, Setor Caravelas, Setor Orientville, Chácaras Talismã I e Talismã II, Residencial Kátia e Residencial Center Ville na região sudoeste de Goiânia - GO, na microbacia do córrego Olho D’Água, professores da Pontifícia Universidade Católica de Goiás em conjunto com alunos pesquisadores da Iniciação Científica, identificaram possíveis focos de fezes de minhocuçus no solo (Figura 10a). Também foi possível notar as semelhanças físicas do solo (cinza e úmido) e relevo de leve inclinação (Figura 10b), como já descritos anteriormente, sobre rochas pré-cambrianas e grande variedade de rochas do embasamento, possui geração de relevos muito aplainados e apresentam-se níveis de lateritas desenvolvidas, que configuram potencial habitat da espécie.

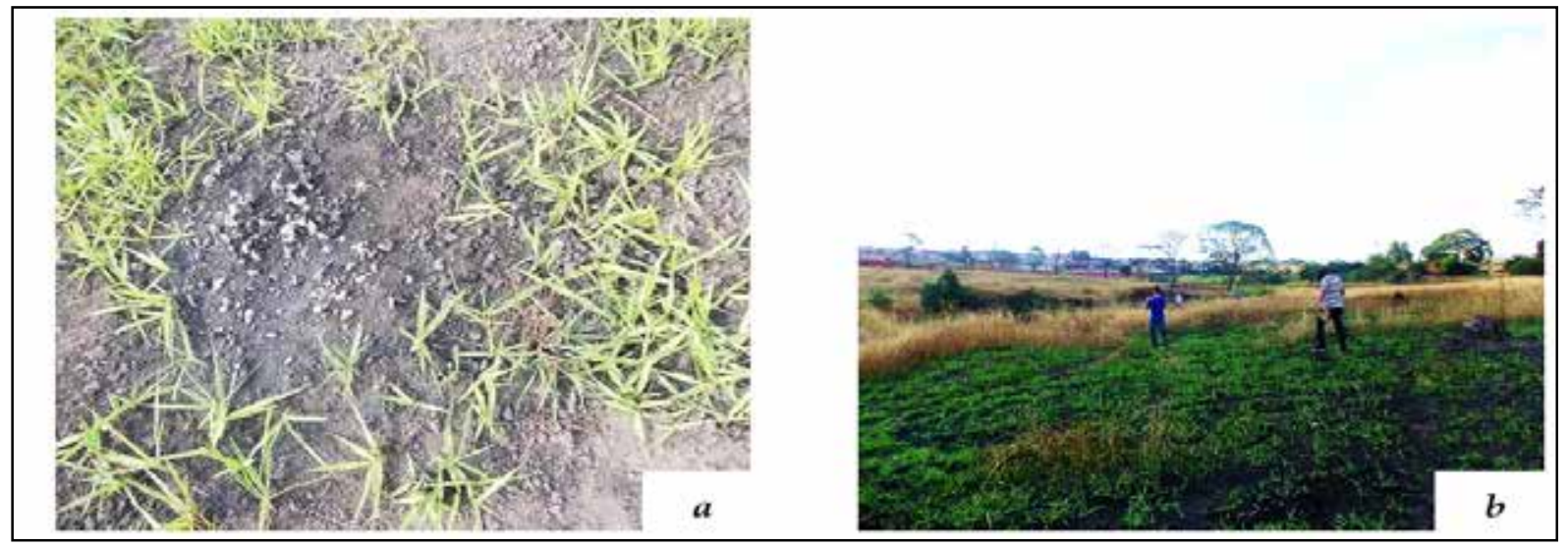

Figura 10 - Comprovação de possível habitat de minhocuçu em Goiânia próximo ao córrego Olho D’Água (a) Excrementos de minhocuçu (ROCHA, 2014); (b) Relevo aplainado (ROCHA, 2014) 
Outro indício de ocorrência de minhocuçu na capital goiana (Figura 11), também na região sudoeste, próximo dos setores Grajaú e Caravelas, microbacia córrego Capão Redondo, também foi percebida por Mendes (2016). Ressalta-se que não foi possível capturar nenhum animal em campo, pois, a área parece ser de propriedade do estado de Goiás, necessitando de autorização para captura e avanço dos estudos, no que diz respeito a identificação correta da espécie existentes no local (Rhinodrilus motucu Righi ou Rhinodrilus fafner Righi).

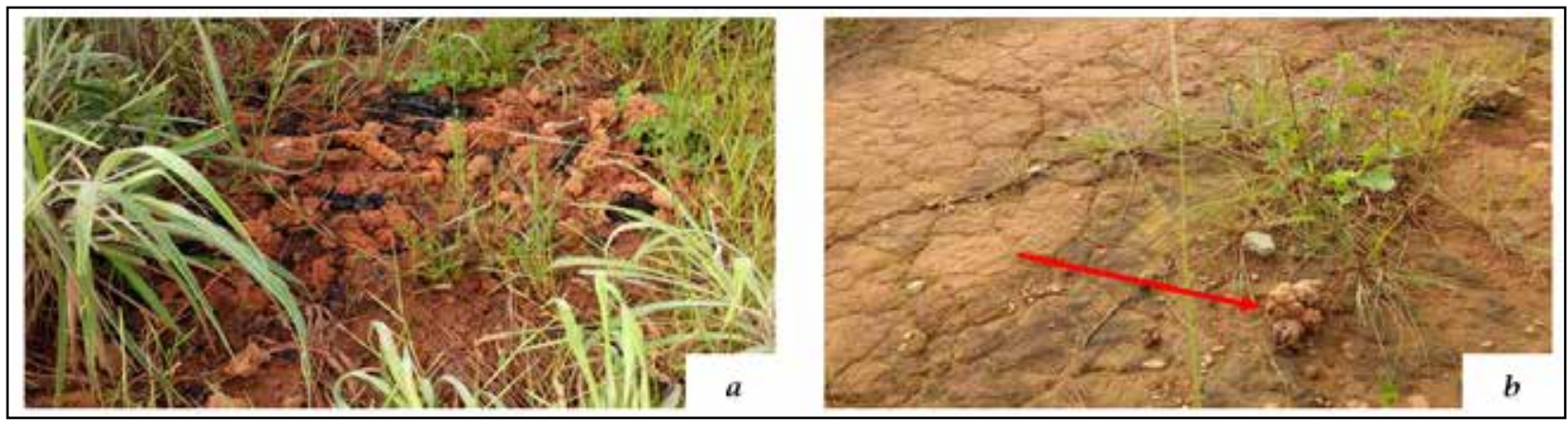

Figura 11 - Outra possível comprovação de habitat de minhocuçu em Goiânia, próximo aos setores Grajaú e Caravelas (a) Excrementos de minhocuçu (MENDES, 2016); (b) Relevo típico aplainado (MENDES, 2016)

Importante fato sobre os indícios de ocorrência da espécie é que, é que os dois lugares descritos anteriormente (região sudoeste do município de Goiânia - GO) são próximos e ambos os córregos Olho D’ Água e Capão Redondo são afluentes do córrego Taquaral que deságua no ribeirão Anicuns e pertencem a bacia do rio Meia Ponte, conforme Figura 12 (ROCHA et al., 2015; MENDES, 2016).

Conforme ITCO (2008, p. 285) na sua revisão e detalhamento da carta de risco e planejamento do meio físico do município de Goiânia, volume VI, sobre a pedologia desta macrozona (ribeirão Anicuns), confirma a predominância de solos do tipo gleissolos/podzólicos (solos aluviais do tipo glei), húmicos, que ocorrem ao longo do canal dos córregos que drenam esta macrozona.

De fato, evidencia-se que o tipo de solo das regiões onde foram relatados (Quadro 1) e encontrados (Figuras 10 e 11) possivelmente os minhocuçus parecem possuir aproximadamente as mesmas características pedológicas e hidrogeológicas.

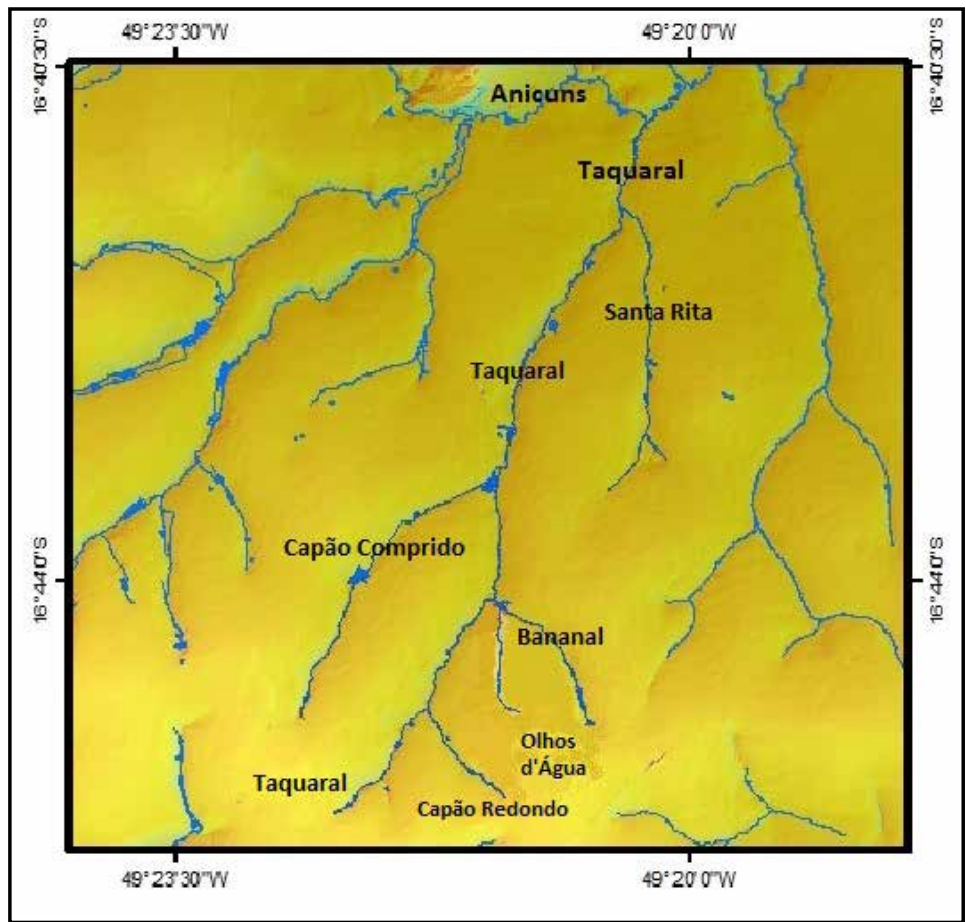

Figura 12 - Parte da rede de drenagem da região sudoeste de Goiânia - GO onde foram identificados a existência de minhocuçus. Fonte: modificado Rocha et al. (2015) 


\section{Conclusões e Recomendações}

A dificuldade em encontrar dados sobre da existência do minhocuçu (Rhinodrilus motucu Righi) no Estado de Goiás, foi um obstáculo para a pesquisa mas, baseando-se nos relatos dos responsáveis pelos Órgãos Ambientais/ Rurais municipais e estaduais e comerciantes de iscas vivas, foi possível conhecer parcialmente a procedência (municípios) onde o animal (minhocuçu) habita. Os relatos orientaram a busca pela comprovação de dados de ocorrência do animal através da análise dos documentos oficiais do Instituto Brasileiro do Meio Ambiente e dos Recursos Naturais Renováveis (IBAMA), Sistema Estadual de Geoinformção de Goiás (SIEG), Serviço Geológico do Brasil (CPRM) e Ministério do Meio Ambiente (MMA).

Ao comparar as informações do mapa de relevo com o mapa de solos e com o livro de geomorfologia do Sistema Estadual de Geoinformação de Goiás - SIEG (LATRUBESSE e CARVALHO, 2006), constatou-se que o ambiente adequado para a ocorrência do minhocuçu pode estar vinculado à ocorrência de rochas pré-cambrianas/rochas do embasamento cristalino. Porém, todos os elementos físicos, químicos, biológicos e mineralógicos que envolvem a formação do solo, são provavelmente fatores limitantes à existência do minhocuçu Rhinodrilus motucu Righi, pois este gênero é geófago, sendo assim, alimenta-se de solos com características peculiares. Observou-se semelhança no solo quanto a presença de laterita, relevo aplainado e solo de cor cinza, que apresentam maior retenção de umidade como é o caso do Gleissolos, Plintossolos e Neossolo, solos estes considerados húmicos, lateríticos e hidromórfos. Outro fator ambiental importante, que foi notado na comparação entre os municípios goianos de Araguapaz, Flores de Goiás e Porangatu é que ainda há áreas de vegetação nativa, do tipo várzea e vereda, presente ao habitat do animal.

Com relação as características do minhocuçu, apontadas pelos responsáveis dos Órgãos Municipais, pescadores e comerciantes de iscas vivas, nota-se que há possibilidade de existir duas espécies distintas no Estado de Goiás. A primeira é o animal em estudo, Rhinodrilus motucu Righi, que habita preferencialmente regiões de veredas e várzeas, ou seja, áreas próximas a cursos d'água, com 25,7 cm de comprimento por 9,5 mm de diâmetro em média, apresentando coloração no dorso de violeta escura, quase negra e o ventre é de tonalidade parda clara. A segunda espécie, assemelha-se às características apresentadas pela Rhinodrilus alatus.

O reconhecimento e a aceitação da população em geral, quanto a necessidade de planejamento e de gerenciamento do uso dos recursos ambientais é trivial à preservação de espécies, em especial, as espécies de minhocuçus. Consoante a isto, sugere-se que deve investir na busca de novos conhecimentos sobre a classificação em que se encontra a espécie motucu no Livro Vermelho (livro sobre as espécies ameaçadas de extinção do IBAMA). Também são importantes os estudos de a reprodução em cativeiro e o manejo adequado das espécies de minhocuçu, principalmente verificando sua alimentação e composição do trato intestinal. Uma proposta aos Órgãos Ambientais é que deve-se analisar a possibilidade de manejo sustentável em área de preservação sustentável, isto por profissionais legalmente registrados e habilitados.

\section{Referências}

BRASIL. Lei nº 5.197, de 3 de janeiro de 1967. Lei de Proteção à Fauna. Diário Oficial da União, Brasília, 1967.

. Lei nº 9.605, de 12 de fevereiro de 1998. Lei de Crimes Ambientais. Diário Oficial da União, Brasília, 1998.

. Lei $n^{\underline{0} 9.985, ~ d e ~} 18$ de julho de 2000. Sistema Nacional de Unidade de Conservação da Natureza (SNUC). Diário Oficial da União, Brasília, 2000.

BROWN, G.; JAMES, S. Ecologia, biodiversidade e biogeografia das minhocas no Brasil. p. 297-381. In: G. G. Brown and C. Fragoso C (Eds.) Minhocas na América Latina: biodiversidade e ecologia. Embrapa Soja, Londrina, 2007.

. Earth worm biodiversity in São Paulo state, Brazil, In. ICSZ - Soil Animals and Ecosystems Services. Proceedings of the XIV th International Colloquium on Soil Biology, European Journal of Soil Biology, Volume 42 , supplement 1. Pages S145-S149. November, 2006.

BROWN, G.; JAMES, S.; MARINI, O. Avaliação do risco de extinção do minhocuçu Rhinodrilus fafner Michaelsen. Biodiversidade Brassileira, 2 (2), 140-144, 2012.

BROWN, G.; JAMES, S.; PASINI, A.; NUNES, D.; BENITO, P.; MARTINS, T.; SAUTTER, K. Exotic, peregrine and invasive earthworms in Brazil: diversity, distribution and effects on soils and plants. Caribbean Journal of Science, 2006. 
CRISCI, J.; KATINAS, L.; POSADAS, P. Historical Biogeography: an introduction. Cambridge, Masssachusetts, Havard University Press. 250p., 2003.

DRUMOND, M.A. Proteção para Minhocas Gigantes. Ciência Hoje. 251, in Press. Rio de Janeiro - RJ, 2008. . Manejo Adaptativo do Minhocuçu. Belo Horizonte - MG: UFMS/ICB, 2008.

FELLER, C.; BROWN, G.; BLANCHART, P.; DELEPORTE, A.; CHERNYANSKI, S. Charles Darwin, earthworms and the natural sciences: various lessons from past to future. Agriculture Ecosystems and Environment. 90: 29-49, 2003.

INSTITUTO DE DESENVOLVIMENTO TECNOLÓGICO DO CENTRO OESTE (ITCO). Revisão e detalhamento da carta de risco e planejamento do meio físico do município de Goiânia: Volume VI - Relatório síntese da macrozona rural do Alto Anicuns. Instituto de Desenvolvimento Tecnológico do Centro Oeste. Prefeitura Municipal de Goiânia - GO, 2008.

INSTITUTO MAURO BORGES (IMB). Estado de Goiás. Disponível em: <http://www.imb.go.gov.br/> Acesso em: 23 de maio de 2013.

JAMES, S.; BROWN, G. Earthworm ecology and biodiversity in Brazil. Pp. 56-116. In: Moreira, F; Siqueira, O. e Brussaard, L. (Eds.) Soil biodiversity in Amazonian and other Brazilian ecosystem. CAB International, Wallingford, 2006.

JONES, C.; LAWTON, J.; SHACHAK, M. Organisms as ecosystem engineers. Oikos, 69:373-386, 1994.

LATRUBESSE, E.; CARVALHO, T. Série Geologia e Mineração 2 - Geomorfologia do Estado de Goiás e Distrito Federal. Secretaria de Indústria de Comércio. Superintendência de Geologia e Mineração. Goiânia/GO. 2006. Disponível em:<http://www.sieg.go.gov.br/downloads/Livro_geomorfologia.pdf >. Acesso em 31 de março de 2014.

LAVELLE, P.; DANGERFIELD, M.; FRAGOSO, C.; ESCHEN-BRENNER, V.; LOPEZHERNANDEZ, D.; PASHANASI, B.; BRUSSARD, L. The relationship between soil mac-rofauna and tropical soil fertility. In: WOOMER, P.L. e SWIFT, M.J., eds. The biological management of tropical soil fertility. New York, Wiley-Sayce Publication, p.137-169, 1994.

LAVELLE, P.; DECAËNS, T.; AUBERT, M.; BAROT, S.; BL-OUIN, M.; BUREAU, F.; MARGERIE, P.; MORA, P.;ROSSI, P. Soil invertebrates and ecosystem services. Soil Biol., 42:3-15, 2006.

LEE, K.E. Earthworms: Their ecology and relationships with soils and land use. Sydney, Academic Press, 1985. 411p.

MENDES, T. A. Imagens da região do setor Grajaú, Goiânia-GO. PUC Goiás, 2016.

MICHAELSEN, W. DieLumbriciden. Zoologische Jahrbucher Abteilungfür Systematik. 41: 1-398, 1918.

MINNICH, J. The earthworm book: how to raise and use earthworms for your farm and garden. Rodale Press, Bethlehem, 1977.

MINISTÉRIO DO MEIO AMBIENTE (MMA). Angelo Barbosa Monteiro Machado, Gláucia Moreira Drummond, Adriano Pereira Paglia. Livro vermelho da fauna brasileira ameaçada de extinção. 1.ed. Brasília, DF: MMA; Belo Horizonte, MG: Fundação Biodiversitas, 2008. 2v. 1420 p. l.(Biodiversidade ; 19) Espécies em extinção - Brasil. 2. Animais silvestres - Brasil.

PRANCE, G.T. The failure of biogeographers to convey the conservationmessage. Journal of Biogeography 27: 51-57, 2000.

RIGHI, G. Sobre a família Glossoscolecidae (Oligochaeta) no Brasil. Arquivos de Zoologia 20 (1): 1-96, 1971.

REDE NACIONAL DE COMBATE AO TRÁFICO DE ANIMAIS SILVESTRES (ReNCTAS). $1^{\circ}$ Relatório Nacional sobre o Tráfico de Fauna Silvestre. Brasília, 2001,108p. Disponível em: http://www.renctas.org.br/pt/trafico/rel_renctas. asp. Acesso: março de 2013. 
ROCHA, W. S.; SANTOS, H. I.; SANTOS, G. M.; CAMPOS, A. C. Avaliação dos Processos Erosivos na Microbacia do Córrego Olho D’água, Município de Goiânia, Goiás. In: VI Congresso Brasileiro de Gestão Ambiental, Porto Alegre, RS, 2015.

ROCHA, W. S. Imagens da região do córrego Olho D’Água em Goiânia-GO. PUC Goiás, 2014.

SANO, E.; DAMBRÓS, L.; OLIVEIRA, G.; BRITES, R. Padrões de Cobertura de Solos do Estado de Goiás. Departamento de Ciências do Solo - Universidade Federal de Lavras. 2004. Disponível em: < http://www.dcs.ufla.br/site/_adm/ upload/file/slides/matdispo/geraldo_cesar/cap_3_padroes $\% 20$ de $\% 20$ cobertura $\% 20$ dos $\% 20$ solos $\% 20$ do $\% 20$ estado $\% 20$ de\%20goias.pdf $>$. Acesso em: 23 de março de 2014.

SCIENTIFIC AMERICA. Brasil - Maior Biodiversidade do Mundo. Edição Especial № 39, Ed. Duetto, São Paulo SP, 2010.

SCHIEDECK, G.; SCHWENGBER, J.; CARDOSO, J.; GONÇALVES, A.; SCHIAVON, L. Aspectos culturais associados às minhocas no Brasil. Acta Zool. Mex vol.26 nº.spe2 Xalapa 2010. Disponível em: <http://www.scielo.org.mx/scielo. php?script-sci_arttext\&pid=S0065>Acesso em: 23 de maio de 2013.

SISTEMA ESTADUAL DE GEOINFORMAÇÃO - SIEG. ARQUIVOS SIG (SHAPEFILE). Disponível em: <http://www. sieg.go.gov.br/> Acesso em: 24 de fevereiro de 2013. 